\title{
Hyperprolinaemia and gyrate atrophy of the choroid and retina in members of the same family
}

\author{
E P DOUGLAS
}

From the Department of Ophthalmology, Royal Infirmary, Glasgow G4 OSF

SUMMARY A report is given of the occurrence of asymptomatic hyperprolinaemia type $I$ in the father of a family in which two of the children have gyrate atrophy of the choroid and retina.

Gyrate atrophy of the choroid and retina is an autosomal recessive disease' due to deficient activity of the enzyme ornithine ketoacid aminotransferase. There is resultant hyperornithinaemia, hyperornithinuria, ${ }^{2.3}$ and hypolysinaemia ${ }^{4}$

The typical eye findings are of circular areas of total choroidal and retinal atrophy, beginning at the periphery. There is hyperpigmentation in the more intact retina around the areas of atrophy. It is associated with myopia, and there may be vitreous opacities. The electroretinogram (ERG) may be initially normal' but with time usually becomes severely depressed or unrecordable. There are abnormalities of electro-oculogram (EOG) and dark adaptation. Defects of the retinal pigment epithelium and choriocapillaris appear on fundus fluorescein angiography.

Generalised manifestations include muscle weakness, abnormal electromyogram (EMG), and atrophy of type II muscle fibres, with tubular aggregates on electron microscopy, ${ }^{5}$ abnormal electroencephalograph (EEG) or seizures ${ }^{6}$ and abnormal ERG.' Clinically these changes are usually mild or absent.

Ornithine aminotransferase is lacking in fibroblasts ${ }^{7}$ and lymphocytes. ${ }^{8}$ This enzyme converts ornithine into $\Delta$-pyrroline-5-carboxylic acid (Fig. 1).

Hyperprolinaemia is an autosomal recessive disease. ${ }^{9}$ There are two types. Type $I$ is due to deficient proline oxidase activity, and type II is due to deficient $\Delta$-pyrroline-5-carboxylic acid dehydrogenase activity (Fig. 1). Both types are usually asymptomatic. In type I cases disease of the renal and central nervous systems, delayed neurological development, seizures, and EEG changes have been recorded, but no direct connection has been estab-

Correspondence to Miss E P Douglas. lished between these manifestations and the disease. ${ }^{9}$ Similarly, some patients with type II hyperprolinaemia have had retarded mental development and seizures, but again no direct association has been established."

\section{BIOCHEMISTRY}

The biochemical relationship between proline and ornithine metabolism is shown (Fig. 1). Proline is a non-essential amino acid. Amino acids occur in the body fluids in the free form and in peptide linkage. Proline is involved in brain metabolism, and cerebrospinal fluid (CSF) proline is increased in type I and type II hyperprolinaemia. ${ }^{9}$ Proline is abundant in its free form, and important pathways provide for its biosynthesis and degradation.

The proline derivative $\Delta$-pyrroline-5-carboxylic acid provides a link between the urea and tricarboxylic acid cycles.

Hydroxyproline, found in peptides and proteins, arises by post-translational modification of peptide proline. Excess proline regulates its metabolism to enhance outflow through the ornithine pathway. Proline competes with hydroxyproline and glycine for a common membrane carrier, which serves their uptake preferentially at concentrations in excess of $0 \cdot 1 \mathrm{mM}$. As either amino acid (proline, hydroxyproline) proceeds to saturate its renal transport system, competitive inhibition of the transport of the other amino acid and glycine occurs. Renal parenchyma has a significant role in proline uptake and metabolism. ${ }^{9}$

Aminoglycinuria (proline, hydroxyproline, glycine) occurs when plasma proline is greater than $0.8 \mathrm{mM}$. The intensity of the aminoglycinuria is proportional to the degree of hyperprolinaemia. Hyperprolinuria results from the progressive saturation of the proline reabsorption sites in the renal 


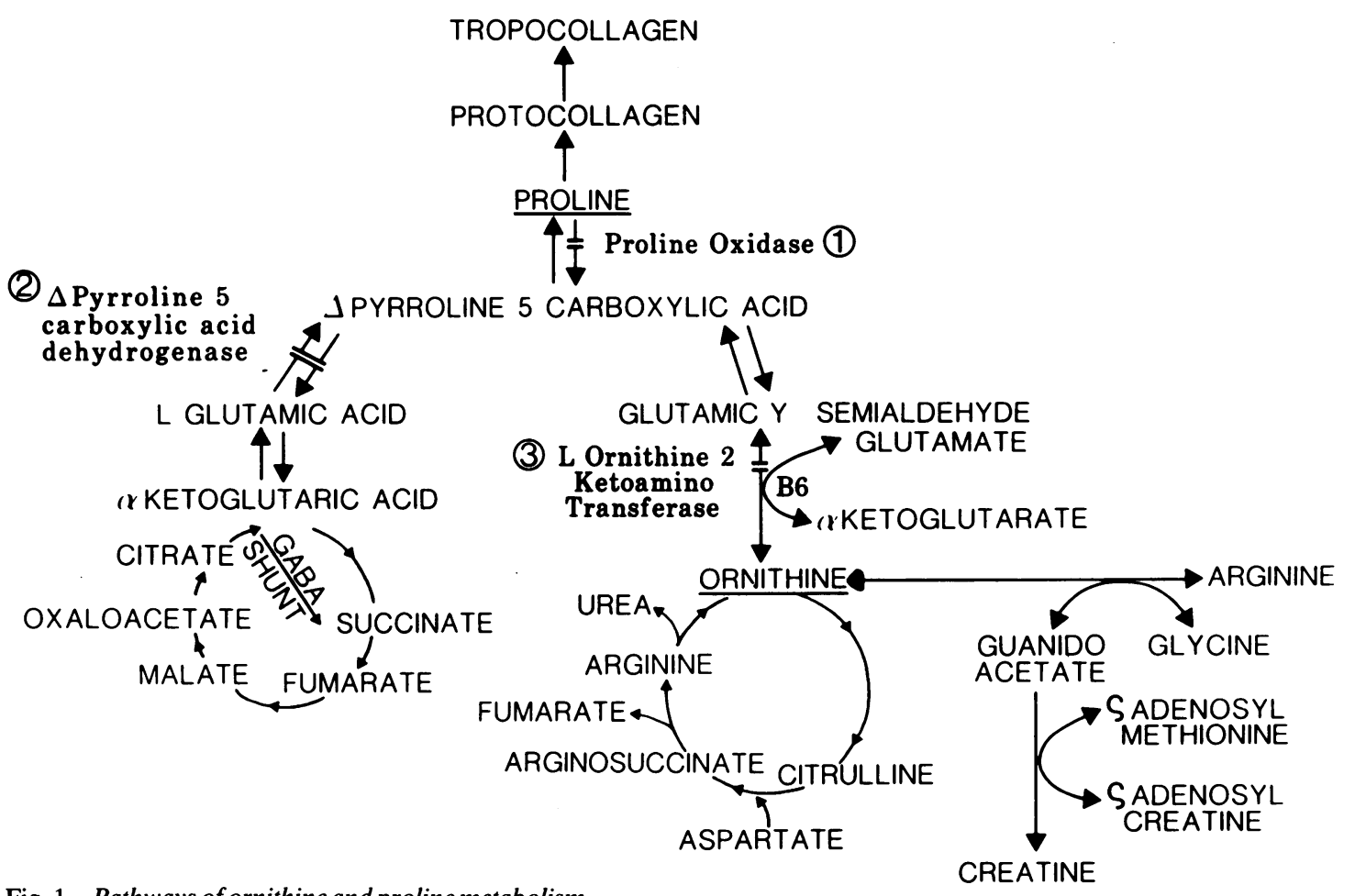

Fig. 1 Pathways of ornithine and proline metabolism.

tubule. Prolinuria thus results from an overflow mechanism. Hyperglycinuria and hyperhydroxyprolinuria is due to a competitive inhibition of the site shared by the three substrates."

Proline accumulation is greater in type II than in type I hyperprolinaemia. The degradation of proline to glutamic acid through the proline intermediary is less efficient than normal in type I hyperprolinaemia. The enzyme proline oxidase involved in type I hyperprolinaemia is a mitochondrial, membrane bound enzyme."

Ornithine arises from dietary or endogenous arginine by (1) action of arginase, (2) the arginineglycine transamidase reaction-the first enzyme in the pathway of creatine synthesis. The major enzymes of ornithine metabolism are intramitochondrial, the ornithine entering the mitochondria through a specific transport system. The major pathway for the disposal of excess ornithine is through the mitochondrial enzyme ornithine ketoacid/ aminotransferase, which needs pyridoxal phosphate as cofactor. ${ }^{10}$ It is this enzyme which is deficient in gyrate atrophy with hyperornithinaemia.

\section{Case reports}

The family under examination consists of father (case 1), mother (case 2), elder son (case 3), younger son (case 4), and daughter (case 5).

The daughter was first seen in 1971 aged 9 years, having been referred because of poor visual acuity. Myopia of mild degree ( -2.0 sphere right eye; -2.5 sphere left eye) was found. Three years later her myopia had increased to a -9.0 sphere with $-0.5 \mathrm{cyl}$ at $20^{\circ}$ in the right eye and -9.0 sphere with $-1.0 \mathrm{cyl}$ at $155^{\circ}$ in the left eye. With this correction her vision was $6 / 9$ in both eyes. Her fundi at this time showed the typical peripheral changes of stage I of gyrate atrophy (Figs. 2a and b). Central field testing gave normal results, but typical concentric constriction of the peripheral fields was present on perimetry.

At that time her younger brother (case 4), aged 8 years, was referred with poor visual acuity. He also had myopia of -3.0 sphere in the right eye and -2.5 sphere in the left. Fundal examination showed an almost identical stage I picture to that of his sister. (Figs. 3a and b). A small retinal operculum was noted in his right eye. Central fields were again full, with peripheral field constriction.

Lens changes were absent in both children. The children were referred for electrophysiology, which was normal. An initial diagnosis of cobblestone degeneration was made.

Although the myopia in both children continued to 


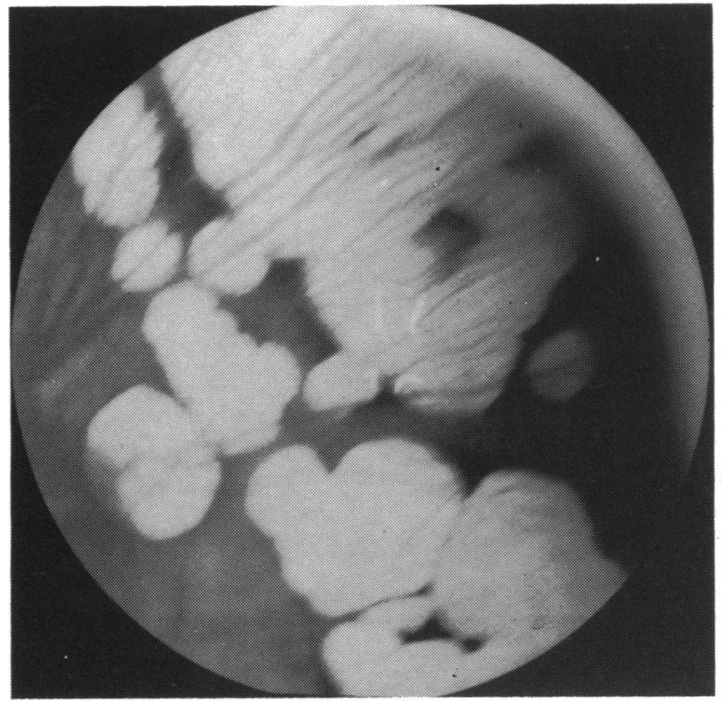

Fig. 2a Fundus of case 5 .

increase, their visual acuity was maintained, and they had no subjective symptoms.

Several years later it was decided to assess their plasma and urinary ornithine levels. A fasting amino acid profile of blood and urine was therefore undertaken. The results are shown in Tables 1 and 2. There was a hyperornithinuria, hyperornithinaemia, and hypolysinaemia, confirming the diagnosis of gyrate atrophy of the choroid and retina, although electrophysiological testing at that time was still normal.

Both children were treated with pyridoxine, which has a lowering effect on plasma ornithine, ${ }^{\text {" and a low }}$ protein diet which amino acid supplements. How-

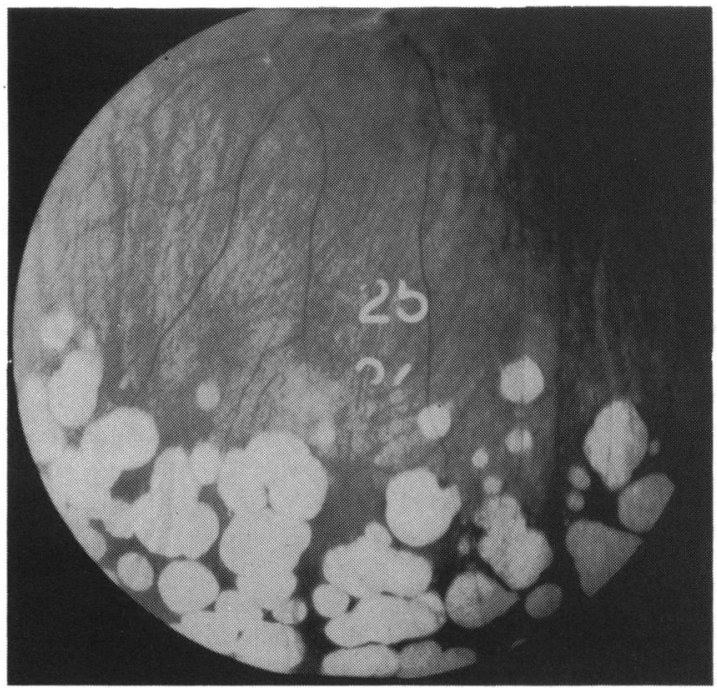

Fig. 3a Fundus of case 4 .

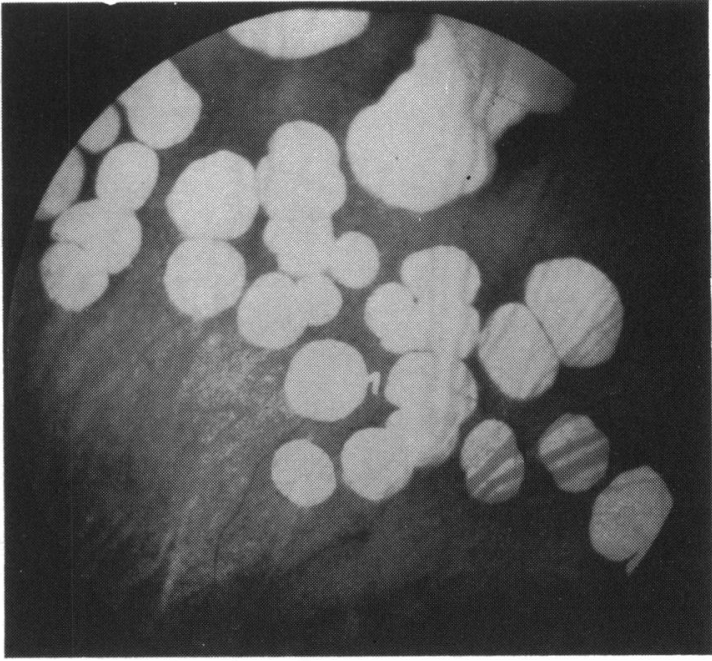

Fig. 2b Fundus of case 5.

ever, this was abandoned because of poor compliance and because of the apparent slow nature of the disease. Fasting amino acid profiles were also undertaken of the father, mother, and elder brother of the affected children (Tables 1,2).

The elder son (case 3) showed an elevated plasma proline and a high normal ornithine level, though urinary levels of these were normal. At the late age of 22 years, this son developed myopia, having previously had normal visual acuity and a normal refraction. The most interesting results were those of the father. The blood sample showed a high normal ornithine as might be expected from the parents,'

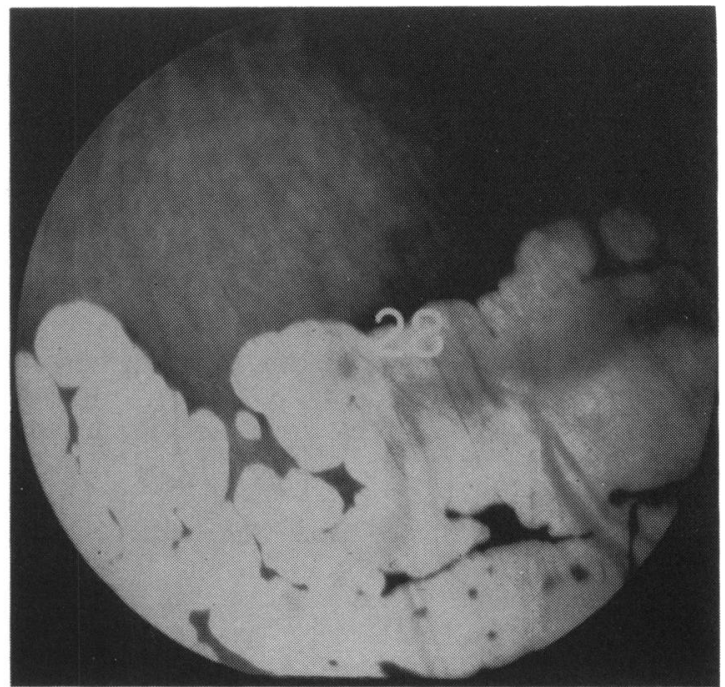

Fig. 3b Fundus of case 4. 
Table 1 Biochemical amino acid profile: plasma

\begin{tabular}{|c|c|c|c|c|c|c|c|c|c|c|c|c|}
\hline \multirow{3}{*}{$\begin{array}{l}\text { Plasma amino acids } \\
\text { in mmol/l } \\
\text { Hydroxyproline }\end{array}$} & \multicolumn{4}{|c|}{ Case I (father) } & \multirow{2}{*}{\multicolumn{2}{|c|}{$\begin{array}{l}\text { Case } 2 \\
\text { (mother) }\end{array}$}} & \multirow{2}{*}{\multicolumn{2}{|c|}{$\begin{array}{l}\text { Case } 3 \\
\text { (elder son) }\end{array}$}} & \multirow{2}{*}{\multicolumn{2}{|c|}{ Case $5^{*}$}} & \multirow{2}{*}{\multicolumn{2}{|c|}{ Case $4^{*}$}} \\
\hline & \multicolumn{2}{|c|}{ Results 1} & \multicolumn{2}{|c|}{ Results 2} & & & & & & & & \\
\hline & ND & - & 21 & $\mathbf{N}$ & ND & - & $41 \cdot 8$ & $\mathrm{HN}$ & $26 \cdot 6$ & $\mathbf{N}$ & $25 \cdot 2$ & $\bar{N}$ \\
\hline Glutamic acid & 104 & $\mathbf{N}$ & $48 \cdot 7$ & $\mathbf{N}$ & 33 & $\mathbf{L N}$ & $75 \cdot 8$ & $\mathbf{N}$ & 111 & $\mathbf{N}$ & 82.6 & $\mathbf{N}$ \\
\hline Proline & 1079 & +++ & 931 & +++ & 281 & $\mathrm{HN}$ & 554 & + & 285 & $\mathrm{HN}$ & 353 & $\mathrm{HN}$ \\
\hline Glycine & 244 & $\mathbf{N}$ & 265 & $\mathbf{N}$ & 214 & $\mathrm{~N}$ & 307 & $\mathbf{N}$ & 228 & $\mathrm{~N}$ & 195 & $\mathbf{N}$ \\
\hline Ornithine & 142 & HN & $92 \cdot 5$ & $\mathbf{N}$ & $89 \cdot 6$ & $\mathbf{N}$ & 139 & HN & $818+$ & ++ & $659+$ & $++t$ \\
\hline Lysine & 193 & $\mathbf{N}$ & 202 & $\mathbf{N}$ & 148 & $\mathbf{N}$ & 135 & $\mathbf{N}$ & $81 \cdot 7$ & - & 99 & LN \\
\hline Arginine & 58.4 & $\mathbf{N}$ & 93.4 & $\mathbf{N}$ & $73 \cdot 1$ & $\mathbf{N}$ & $42 \cdot 8$ & $\mathbf{L N}$ & 76 & $\mathbf{N}$ & 83.1 & $\mathrm{~N}$ \\
\hline
\end{tabular}

*Patients affected with gyrate atrophy.

$+=$ increased. $-=$ decreased. $\mathrm{HN}=$ high normal. $\mathrm{LN}=$ low normal. $\mathrm{N}=$ normal. $\mathrm{ND}=$ none detected.

who are often obligate heterozygotes. ${ }^{12}$ However, it also showed a markedly elevated plasma proline level. Proline and ornithine levels were normal in his urine (Tables 1,2).

Further fasting blood and urine samples were taken from the father. (Results 2 in Tables 1,2 ) to establish the type of hyperprolinaemia. The plasma again showed a high proline level, though the urine showed only a high normal level. There was no increase in the excretion of $\Delta$-pyrroline-5-carboxylic acid as would occur in type II hyperprolinaemia. It was therefore concluded that this was a type I hyperprolineamia. Further provocative testing with ornithine loading in both parents ${ }^{1}$ was unfortunately impossible for economic and social reasons.

The visual progress of the two affected children, the girl now aged 20 years, and the younger son aged 16 years, remains surprisingly good. Their fundal appearances are still those of stage I. They are considerably hindered by night blindness, and their perimetry shows considerable constriction, although their central fields remain full. Normal visual acuity is maintained with their myopic correction. Dark adaptation tests are only moderately abnormal. Recent ERG and EOG examinations have not been possible because of poor compliance.

BIOCHEMICAL METHODOLOGY

The biochemical tests were performed on fasting subjects, and consisted of a blood sample and 24hour collection of urine.

Deproteinisation of plasma prior to aminoacid analysis was employed by using $50 \mathrm{mg}$ of salicylsulphonic acid per ml plasma. Urine specimens were treated similarly to adjust the $\mathrm{pH}$ prior to application to the resin column. A Technicon TSM amino acid analyser was employed with separation of the individual plasma amino acids requiring approximately $61 / 2$ hours. A Wang 2200 computer was used to process and evaluate the results obtained from the analyser. The findings were assessed against agerelated reference ranges with the symbols $\mathrm{N}, \mathrm{HN},+$ or - being appended. Those results with + or -1 standard deviation (SD) of expected mean values were shown as $\mathrm{N}$, those between $+1 \mathrm{SD}$ and $+2 \mathrm{SDs}$ as $\mathrm{HN}$, and those between +2 SDs and +3 SDs as + etc.

The reference ranges for fasting plasma proline, hydroxyproline, and ornithine concentrations in subjects aged 8 or 9 and in adults are shown in Table 3 .

\section{Discussion}

For social, psychological, and economic reasons it was not possible to carry out full investigations in this family, including enzyme studies and loading tests. However, the genotype of some family members with respect to hyperprolinaemia on the one hand and

Table 2 Biochemical amino acid profile: urine

\begin{tabular}{|c|c|c|c|c|c|c|c|c|c|c|c|c|}
\hline \multirow{2}{*}{$\begin{array}{l}\text { Urine amino acids } \\
\text { in mmol/l }\end{array}$} & \multicolumn{4}{|c|}{ Case I (father) } & \multirow{2}{*}{\multicolumn{2}{|c|}{$\begin{array}{l}\text { Case } 2 \\
\text { (mother) }\end{array}$}} & \multirow{2}{*}{\multicolumn{2}{|c|}{$\begin{array}{l}\text { Case } 3 \\
\text { (elder son) }\end{array}$}} & \multirow{2}{*}{\multicolumn{2}{|c|}{ Case $5^{*}$}} & \multirow{2}{*}{\multicolumn{2}{|c|}{ Case $4^{*}$}} \\
\hline & \multicolumn{2}{|c|}{ Results 1} & \multicolumn{2}{|c|}{ Results 2} & & & & & & & & \\
\hline Hydroxyproline & ND & - & $2 \cdot 7$ & $\mathbf{L N}$ & ND & - & ND & - & ND & - & ND & - \\
\hline Proline & $6 \cdot 6$ & $\mathbf{N}$ & $8 \cdot 5$ & HN & $2 \cdot 1$ & LN & $2 \cdot 8$ & $\mathbf{N}$ & 3.9 & $\mathbf{N}$ & 6 & $\mathbf{N}$ \\
\hline Glycine & 190 & $\mathbf{N}$ & 259 & $\mathbf{N}$ & 122 & $\mathbf{N}$ & 177 & $\mathbf{N}$ & 299 & HN & 230 & $\mathbf{N}$ \\
\hline Ornithine & 23 & $\mathbf{N}$ & ND & $\mathbf{L N}$ & $1 \cdot 7$ & $\mathbf{N}$ & 1.9 & $\mathbf{N}$ & 105 & ++++ & 175 & $+t$ \\
\hline Lysine & $27 \cdot 2$ & $\mathbf{N}$ & $26 \cdot 5$ & $\mathbf{N}$ & $16 \cdot 8$ & $\mathbf{N}$ & $16 \cdot 8$ & $\mathbf{N}$ & $53 \cdot 2$ & $\mathrm{HN}$ & 76 & HN \\
\hline
\end{tabular}

${ }^{*}$ Patients affected with gyrate atrophy.

$+=$ increased. $-=$ decreased. $\mathrm{HN}=$ high normal. $\mathrm{LN}=$ low normal. $\mathrm{N}=$ normal. $\mathrm{ND}=$ none detected. 
Table 3 Plasmaaminoacids ( $\mu$ mol/l)

\begin{tabular}{|c|c|c|c|c|c|}
\hline & Age & $\begin{array}{l}\text { Geometric } \\
\text { mean }\end{array}$ & $\pm 1 S D$ & $\pm 2 S D$ & $\pm 3 S D$ \\
\hline Proline & $\begin{array}{l}3-12 \mathrm{yr} \\
>12 \mathrm{yr}\end{array}$ & $\begin{array}{l}192 \cdot 7 \\
192 \cdot 4\end{array}$ & $\begin{array}{l}118 \cdot 3-313 \cdot 9 \\
134 \cdot 8-274 \cdot 8\end{array}$ & $\begin{array}{l}72 \cdot 6-511 \cdot 2 \\
94 \cdot 4-392 \cdot 3\end{array}$ & $\begin{array}{l}44 \cdot 6-832 \cdot 6 \\
66 \cdot 1-560\end{array}$ \\
\hline Hydroxyproline & $\begin{array}{l}3-12 \mathrm{yr} \\
>12 \mathrm{yr}\end{array}$ & $\begin{array}{l}30 \cdot 2 \\
23 \cdot 4\end{array}$ & $\begin{array}{l}17 \cdot 7-51 \cdot 5 \\
16 \cdot 3-33 \cdot 4\end{array}$ & $\begin{array}{l}10 \cdot 4-87.9 \\
11.4-47.7\end{array}$ & $\begin{array}{l}6 \cdot 1-150 \\
8 \cdot 0-68 \cdot 2\end{array}$ \\
\hline Ornithine & $\begin{array}{l}3-12 \mathrm{yr} \\
>12 \mathrm{yr}\end{array}$ & $\begin{array}{l}67 \cdot 3 \\
85 \cdot 9\end{array}$ & $\begin{array}{l}36 \cdot 4-124 \cdot 5 \\
58 \cdot 1-126 \cdot 8\end{array}$ & $\begin{array}{l}19 \cdot 7-230 \cdot 2 \\
39 \cdot 4-187 \cdot 4\end{array}$ & $\begin{array}{l}10 \cdot 6-425 \cdot 8 \\
26 \cdot 6-276 \cdot 8\end{array}$ \\
\hline
\end{tabular}

gyrate atrophy on the other may be inferred from the available data.

On the basis of the above results the father would appear to be suffering from type I hyperprolinaemia. It is somewhat surprising that he shows no aminoaciduria; indeed his hydroxyproline levels are undetectable and are therefore reduced from normal levels, as indeed they are in all three of his children. This may be explained by a relatively high renal threshold for proline.

As the father appears to have hyperprolinaemia type $I$, it would be expected that each of his offspring would be heterozygous for this condition, and it is of interest that his elder son (case 3) showed a raised plasma proline level and his other son and daughter (cases 4 and 5) showed high normal levels. However, it may also be noted that his wife also showed a high normal proline level. Moreover in two patients affected with gyrate atrophy in two families studied by Yatziv $e a^{\prime l^{2}}$ levels of $210 \mu \mathrm{mol} / \mathrm{l}$ and $185 \mu \mathrm{mol} / \mathrm{l}$ were recorded. These correlate with the reading for the daughter.

The plasma proline levels in patients with gyrate atrophy tend to be normal and their tissue levels tend to be low..$^{112}$ The elder brother and sister (cases 3 and 5) appear to have gyrate atrophy with hyperornithaemia, based on the high plasma levels or ornithine, increasing myopia, night blindness, and fundus appearances, typical of gyrate atrophy. The parents must be assumed to be obligate heterozygotes, and, although the high normal plasma ornithine in their elder son (case 3 ) might suggest that he is also a heterozygote, it is not possible to conclude this without further tests.

This family is of interest in that the members of consecutive generations have two genetically distinct rare recessive disorders which involve enzyme deficiencies affecting related metabolic pathways. The enzymes concerned are both mitochondrialproline oxidase residing in the inner mitochondrial membrane, and ornithine ketoacid aminotransferase residing in the mitochondrial matrix. Although it is possible that some members of the family were heterozygous for each condition, or homozygous for one and heterozygous for the other, there is nothing in the present study to suggest an interaction between the two metabolic disorders.

I am extremely grateful to Dr Robert W Logan, consultant medical biochemist, and his staff at Yorkhill Children's and Maternity Hospital, Glasgow, for their invaluable help and assistance regarding the complex biochemistry involved in this paper and also for the biochemical methodology.

\section{References}

1 Takki K, Simelli O. Genetic aspects in gyrate atrophy of the choroid and retina with hyperornithinaemia. $\mathrm{Br} J$ Ophthalmol 1974; 58: 907-16.

2 Simelli O, Takki K. Raised plasma ornithine and gyrate atrophy of the choroid and retina. Lancet 1973; i: 1031-3.

3 Takki K. Gyrate atrophy of the choroid and retina associated with hyperornithinaemia. Br J Ophthalmol 1974; 58: 3-23.

4 Berson EJ, Schmidt SY, Rabin AR. Plasma amino acids in hereditary retinal disease: ornithine, lysine, taurine. $\mathrm{Br} J$ Ophthalmol 1976; 60: 142-7.

5 Siphilia I, Simell O, Rapola J, Saimio K, Tuuteri L. Gyrate atrophy of the choroid and retina with hyperornithinaemia, tubular aggregates and type 2 fibre atrophy in muscle. Neurology 1979; 29: 996-1005.

6 Kaiser-Kupfer MI, Askanas V, Kuwabara T, et al. Systemic manifestations of gyrate atrophy of the choroid and retina. Presented at the 85th Annual Meeting of the American Academy of Ophthalmology, Chicago. 5 November 1980.

7 Trijbels JMF, Sengers JAJM, Bakkeren AFM, De Kori, Deutman AF. L-ornithine-ketoacid-transaminase deficiency in cultured fibroblasts of a patient with hyperornithinaemia and gyrate atrophy of the choroid and retina. Clin Chim Acta 1977; 79: 371-7.

8 Valle D, Kaiser-Kupfer MI, Del Valle LA. Gyrate atrophy of the choroid and retina: deficiency of ornithine aminotransferase in transformed lymphocytes. Proc Natl Acad Sci USA 1977; 74: 5159-61.

9 Scriver CR. Disorders of proline and hydroxyproline metabolism. In: Stanbury JB, Syngaarden JB, Frederickson DS, eds. The metabolic basis of inherited disease. 4th ed. New York: McGraw Hill, 1978: 336-61.

10 Weleber RG, Kennaway NG, Buist NRM. Gyrate atrophy of the choroid and retina-approaches to therapy. Int Ophthalmol 1981; 4: 23-32.

11 Weleber RG, Kennaway NG, Buist NRM. Vitamin $B_{6}$ in management of gyrate atrophy of the choroid and retina. Lancet 1978; ii: 1213.

12 Yatziv S, Statter M, Merin S. Metabolic studies in two families with hyperornithinaemia and gyrate atrophy of the choroid and retina. J Lab Clin Med 1979; 93: 749-57. 